\title{
The Research on Temporal-Spatial Distribution and Morphological Characteristics of Ancient Ruins in Shaanxi Province
}

\section{Zhengwei Li ( $\sim 2473442672 @ q q . c o m$ )}

XinYang University

Research article

Keywords: Shaanxi province, tombs, GIS, space analysis, temporal-spatial distribution

Posted Date: May 11th, 2021

DOl: https://doi.org/10.21203/rs.3.rs-485252/v1

License: (c) (1) This work is licensed under a Creative Commons Attribution 4.0 International License.

Read Full License 


\section{The Research on Temporal-Spatial Distribution and Morphological Characteristics of Ancient Ruins in Shaanxi Province}

\section{Zhengwei Li}

XinYang University, Xin' yang 464000, China; 2473442672@qq.com

Abstract: This paper uses the spatial analysis method of GIS to study the temporal-spatial distribution characteristics of ancient sites from the Han to the Tang periods in Shaanxi Province. (1) Analysis of topographic features reveals that ancient sites in Shaanxi Province are concentrated in plain areas with slopes due south, east, and southeast, elevations of about $866 \mathrm{~m}$, and slopes of 0 to $3^{\circ}$. (2) From the point line analysis, founding the sites are concentrated in the range of $10 \mathrm{~km}$, the farther away from the river, the fewer tombs distributed, it shows that the distribution of ancient tombs is linear. (3) The final kernel density analysis found that the site sites from the Han to the Northern and Southern Dynasties were concentrated in the Guanzhong Plain, while the distribution in other areas was more scattered; In the Sui and the Tang Dynasties, the sites were mainly distributed in Guanzhong Plain with $\mathrm{Xi}^{\prime}$ an as the center. Studying the temporal-spatial distribution characteristics of ancient sites can not only explore the relationship between the development of ancient human society and the evolution of the natural environment but also provide a reference for the further study of sites in the future.

Key words: Shaanxi province; tombs; GIS; space analysis; temporal - spatial distribution

\section{Introduction}

As an important cultural relic left by human activities, ancient sites are of great research value and have produced numerous research achievements. Foreign scholars mainly study focus on the digital construction of ancient sites, secondary innovation, and the establishment of a protection fund system [1-3]; Domestic scholars mainly study focus on the spatial distribution, formation reasons, protection mechanism, and tourism development of ancient sites $[4,5]$. For example, 《Distribution of Neolithic Sites and Environmental Change in Huaihe River Basin, Anhui Province》 [6]、 《Distribution Patterns of the Ancient Cultural Sites in the Middle Reaches of the Yangtze River since 8500 a BP》 [7] 《 《Temporal-Spatial Distribution of Mining Heritages in China: the Perspective of Officially Protected Site/Entity》 [8] 《 《Spatio-Temporal Characteristics and Impacting Factors of Historic Gardens in China》 [9]、 《Tourism and Heritage Protection: a Case-based Theoretical Study》 [10]. With the development of geographic information technology, providing advanced technical support for the study of temporal-spatial distribution of the ancient sites.

Shaanxi Province has a long history, and 13 dynasties established their capitals in Xi'an. 
During the Han Dynasty, Chang'an was the most prosperous and populous international city in the world, there are many ancient sites left by human activities. At present, the research on the ancient sites in Shaanxi Province is mostly in the fields of history [11], archaeology [12], anthropology [13], climatology, and sedimentology [14], while the research from the perspective of geography is rare $[15-17]$. In this paper, the powerful spatial analysis function of ArcMap is used to process the data of modern topography and administrative division of Shaanxi Province, and the ancient sites from Han to Tang Dynasty and the modern geographical environment are superimposed and analyzed to explore the temporalspatial distribution characteristics of ancient sites, to provide the basis for the research and protection of ancient sites.

\section{Methods}

\subsection{Study area}

Shaanxi Province is located in the northwest of China, with 10 prefecture-level cities. It borders on 7 provinces of Shanxi, Henan, Hubei, Sichuan, Gansu, Ningxia, Inner Mongolia, and one municipality, Chongqing. There are plateau, plain, mountain area, hills, basins, sandstorm landforms, and other landforms. The Northern Shaanxi Plateau is dominated by a warm temperate semi-humid climate, Guanzhong Plain belongs to the north subtropical humid climate, Qinba Mountain belongs to a warm temperate humid climate. Affected by the topography, the annual precipitation is less in the north and more in the south, increasing from $300 \mathrm{~mm}$ in the north of Shaanxi to $1700 \mathrm{~mm}$ in the Qinba Mountain area. Shaanxi Province is the gate of Northwest China, also adjacent to nomads, geographical location is very important. It has always been a place for military strategists. The ancient sites produced by cultural blending need to be paid attention to by experts and scholars.

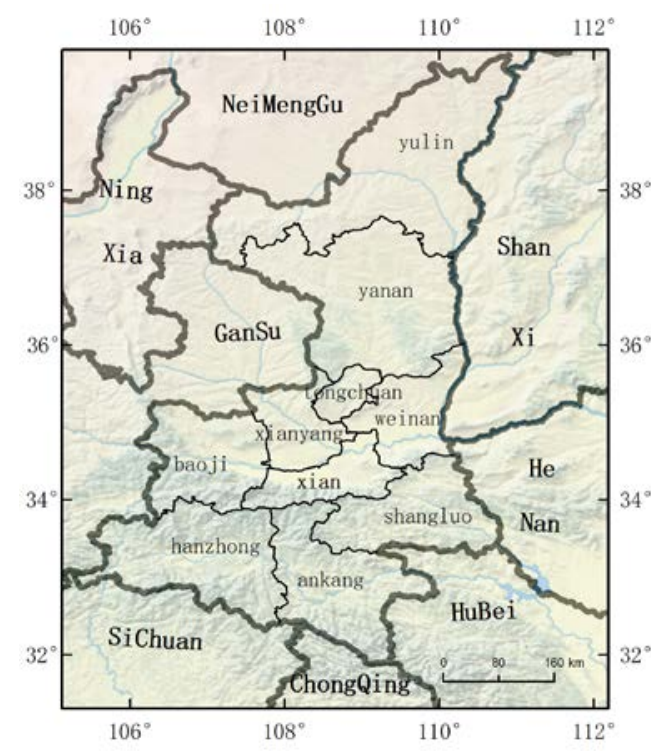

Fig. 1 Location-based map of Shaanxi

\subsection{Data sources and research methods}

The data of ancient sites mainly come from the series of the third national cultural relics 
census in Shaanxi Province [18], The book consists of 11 rolls and 107 volumes, was compiled by Shaanxi Provincial Bureau of cultural relics took four years, employing more than 6000 professional and technical personnel through field investigation. Part of the data comes from archaeological surveys and excavation briefs [19].Through the description of the location of ancient sites in books, finding the corresponding site on Google Earth. In the process, a few sites with unclear descriptions were abandoned, using the GIS data conversion tool to import site points into ArcMap. In addition to historical data, there are vector data and raster data. The vector data comes from the 1:4 million Shaanxi administrative line and area data provided by the official website of the National Center for Basic Geographic Information; The raster data is from DEM (digital elevation model) data of Shaanxi Province with resolution of $30 \mathrm{~m}$ provided by Geospatial Data Cloud Platform. Studying the temporalspatial distribution of ancient sites in Shaanxi Province from Han Dynasty to Tang Dynasty, it is necessary to obtain the natural geographical environment at that time, but the geographical environment in the historical period is not available, only select the modern DEM data and administrative boundaries as the basic data to analyze the temporal-spatial distribution characteristics of ancient sites. Although there are differences between the Natural Geographical Environment of modern Shaanxi Province and that of the Han and Tang Dynasties, the modern geographical environment is evolved based on the historical environment, and the overall framework has not changed greatly. Therefore, it is necessary to study the temporal-spatial distribution of ancient sites with the modern geographical environment, although there are some errors [20]. Referring to the historical classification of chronology system and Archaeology system, the time of this study can be divided into two periods: Han Dynasty to Southern and Northern Dynasties and Sui Dynasty to Tang Dynasty.

To study the relationship between the temporal-spatial distribution of ancient sites and their geographical location and environment, In ArcMap, the data of ancient sites converted from Google Earth into vector points (divided into Han Southern and Northern Dynasties and Sui Tang Dynasties), the administrative boundary of Shaanxi Province and DEM data are imported. Through the reclassification of DEM data, the elevation, slope, and aspect data are obtained, then, the spatial analysis tool of ArcMap is used to identify and overlay the ancient sites, to draw the temporal-spatial distribution map and the statistical table of elevation, slope and aspect of the sites from Han Dynasty to Southern and Northern Dynasties and Sui Dynasty to Tang Dynasty. Combined with natural and human factors such as topography, climate and precipitation, regime change, economic development and population, this paper discusses the relationship between the temporal-spatial distribution characteristics of ancient sites with geographical location and environment.

\section{Analysis}

\subsection{Temporal-spatial distribution characteristics}

After sorting out the data of the third general survey of cultural relics in Shaanxi Province, 1937 sites were found, and there are 1594 sites from the Han Dynasty to the 
Southern and Northern Dynasties and 374 sites from the Sui and Tang Dynasties, of which 34 sites belong to two historical periods. There are a large number of cultural relics from Han Dynasty to Tang Dynasty in Shaanxi Province. The types include grottoes, temples, stone carvings, ancient buildings, ancient tombs, and ancient sites, among which a large number of ancient sites have been found. This paper studies the spatial distribution of ancient sites through the spatial analysis function of GIS and then observes whether the sites have spatial aggregation. Using the nuclear density analysis tool to analyze the sites' density, after many experiments, the pixel size of 0.1 and radius of $1 \mathrm{~km}$ were selected as the search area. The results are shown in Figure 2.

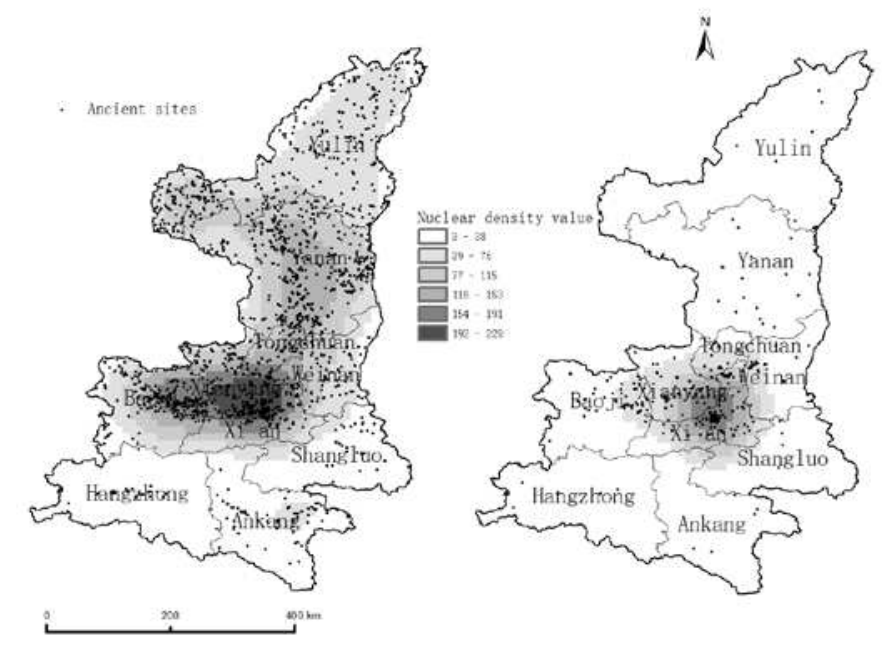

Fig.2 Density of ancient sites in the Han dynasties-Northern and Southern dynasties(left) and in the Sui dynasties-Tang dynasties (right)

It can be seen from Figure 2 that there are similarities and differences in the number and distribution of sites from the Han Dynasty to the Southern and Northern Dynasties and the Sui and Tang Dynasties. From Han Dynasty to the Southern and Northern Dynasties, the number of sites accounts for $82.3 \%$ of the total, the number of sites in the Han Dynasty was the largest. During this period, the sites are mainly distributed in Xi'an and Xianyang City, followed by Baoji and the Northern Shaanxi Plateau, the distribution in southern Shaanxi is less and irregular. The number of sites in the Sui and Tang Dynasties accounted for $17.7 \%$ of the total, the sites were concentrated in Xi'an and Xianyang City, and scattered in other areas. From Han Dynasty to Southern and Northern Dynasties, Sui and Tang Dynasties, the reason of this distribution is closely related to the topography, climate, and precipitation, regime change, economic development, and population of Shaanxi Province. There are many landforms in Shaanxi Province: plateau, sandstorm, plain, hill, mountain, and basin. Among them, the Northern Shaanxi Plateau is located at the junction of nomadic culture and farming culture, and cultural integration produces ancient sites. Because of the bad climate and environment in Northern Shaanxi, there is no gathering and distribution of sites. The Guanzhong Plain, with Xi'an as the center, is flat. Xi'an is the ancient capital of the thirteen dynasties, with developed economy, large population, and suitable geographical environment for people to live in. The traffic in the mountainous area of Southern Shaanxi is 
inconvenient, and only the basin in the mountainous area is suitable for living. Therefore, sites from Han Dynasty to Southern and Northern Dynasties, Sui and Tang Dynasties are concentrated in Guanzhong Plain. From the Han Dynasty to the Southern and Northern Dynasties, a small number of sites were concentrated in the basin areas of Ankang and Hanzhong City.

In terms of climate, the historical period from the Western Han Dynasty to the Sui Dynasty was dry and cold [21], the climate is bad. The Han Dynasty is a unified empire in China, with a prosperous economy and culture and a large population. During the period of Wei, Jin, Southern, and Northern Dynasties, the society was turbulent, and the population decreased sharply due to war, famine, and pestilence [22]. Therefore, from Han Dynasty to Southern and Northern Dynasties, the number of ancient sites in the Han Dynasty is far more than that in the Wei, Jin and Southern and Northern Dynasties. During the Sui and Tang Dynasties, the climate was warm and suitable for people's lives. However, this period lasted only 300 years, so the number of ancient sites is far less than that from Han Dynasty to Southern and Northern Dynasties. In ancient times, science and technology were backward, people had a reverence for nature, had a low ability to transform nature, and lived in the natural environment. People choose to live in groups, help each other, and resist natural disasters together, so the ancient sites present the characteristics of aggregated distribution.

\subsection{Influence factors on the distribution of site locations}

In ancient society, people relied heavily on the natural environment, especially the geographical environment, including altitude, slope, aspect, and river. Altitude has a direct impact on climate, precipitation, and landform, and then affects economy and habitability; The slope involves the height of the terrain, the area with small slope belongs to plain or basin, which is suitable for people to live, while the area with large slope belongs to the mountain, which is not suitable for people to live; The slope direction involves the sunlight illumination, in the northern hemisphere, due south, southwest and Southeast belong to sunny slope, which is suitable for people to live; due east, due west and northeast belong to shady slope, which is not suitable for people to live; Rivers are closely related to ancient human activities [23], influenced by the ancient water intake technology and flood control technology, people would choose to live near but not close to the river. For example, the high altitude of Northern Shaanxi Plateau has a large temperature difference between day and night, with bad wind and sand environment, and the precipitation is rare, it is not suitable for people to live, so the Northern Shaanxi plateau with much land and few people. Therefore, to study the temporal-spatial distribution characteristics of ancient sites, we must make a detailed analysis of the geographical environment. In ArcMap, the temporal-spatial distribution characteristics of sites are studied by kernel density, reclassification, slope, aspect, buffer analysis, and distance analysis of the terrain where the sites are located.

\subsubsection{Elevation}


Through the data management tool of ArcMap software, the DEM of Shaanxi Province is projected and symbolized, loading vector data of sites from Han to Southern and Northern Dynasties and Sui and Tang Dynasties, drawing elevation distribution map. Identifying elevation of the sites and the elevation data of each site is obtained, and the elevation frequency map is made.

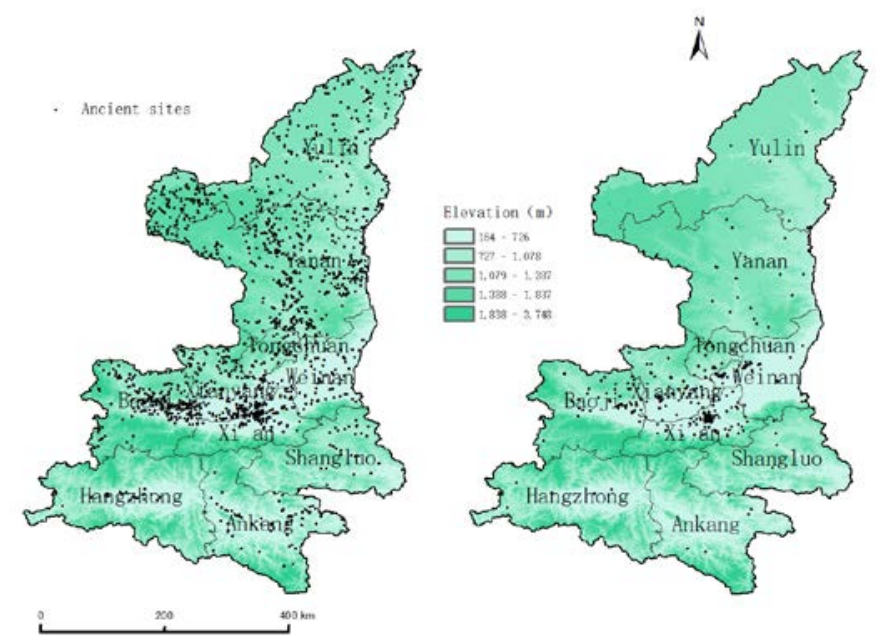

Fig.3 Altitude of ancient sites in the Han dynasties-Northern and Southern dynasties(left) and in the Sui dynasties-Tang dynasties (right)

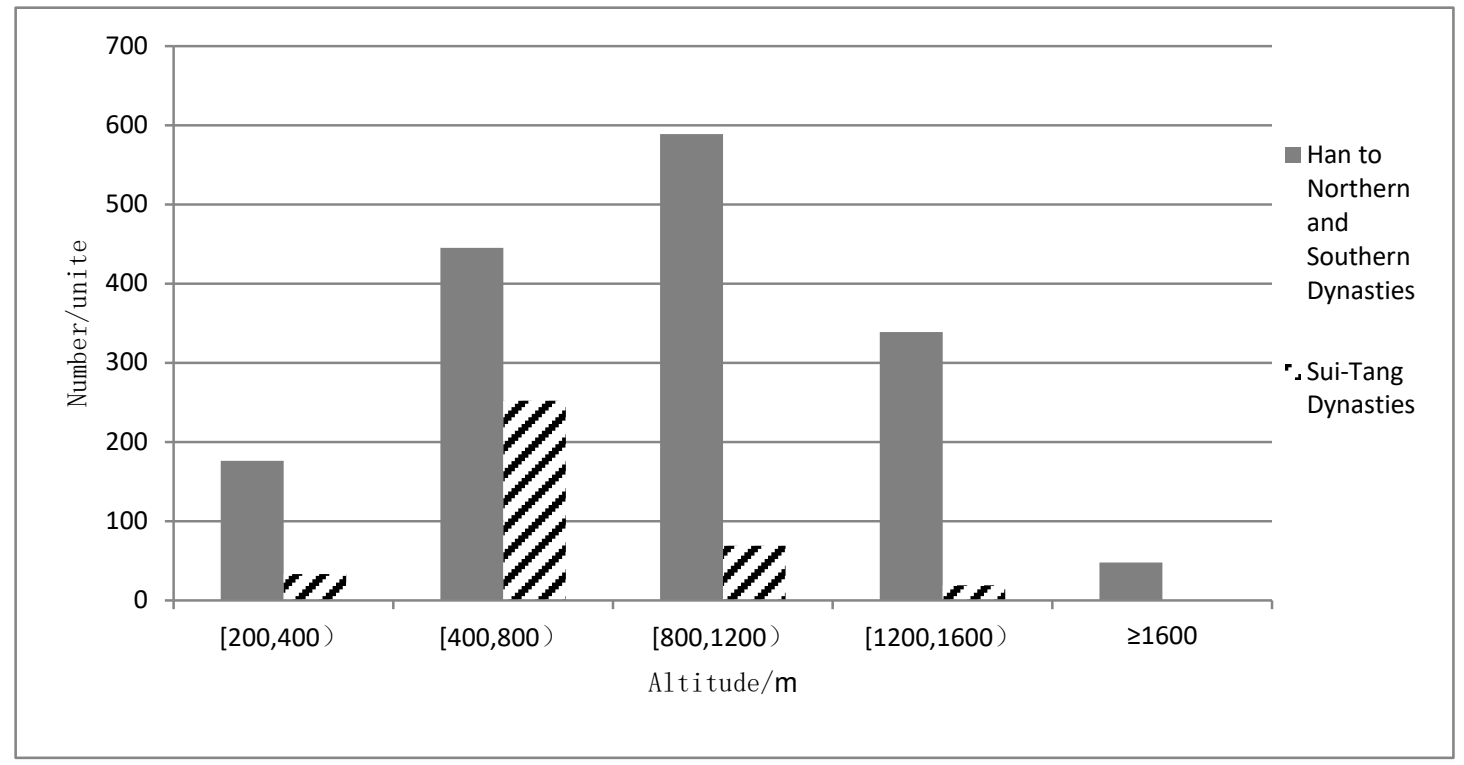

Fig.4 Altitude frequency chart of ancient sites

From Figure 3 and Figure 4, it can be seen that there are 176 and 33 ancient site points distributed between 200 400m above sea level in Shaanxi Province during the Han to North and South Dynasties and the Sui and Tang Dynasties, accounting for $11.0 \%$ and $8.8 \%$ of the total number of sites in each period, respectively; There are 445 and 252 sites distributed between 400 and $800 \mathrm{~m}$ above sea level, accounting for $27.9 \%$ and $67.4 \%$ of the total number of sites in each period, respectively; 589 and 69 sites distributed between 800 and 1200m above sea level, accounting for $36.9 \%$ and $18.4 \%$ of the total number of sites in each period, respectively; 339 and 19 sites distributed between 1200 and 1600m above sea level, accounting 
for $21.2 \%$ and $5.1 \%$ of the total number of sites in each period, respectively. There are 339 and 19 points distributed between 1200 and $1600 \mathrm{~m}$ above sea level, accounting for $21.2 \%$ and $5.1 \%$ of the total number of sites in each period, respectively. There are 48 and 1 points with elevation greater than 1600 , accounting for $3.0 \%$ and $0.3 \%$ of the total number of sites in each period, respectively. Conclusion: The number of sites decreases with increasing altitude in both periods after the altitude is greater than $1200 \mathrm{~m}$. The average elevation of the site points from Han to North and South Dynasties is $917.8 \mathrm{~m}$, and the average elevation of the site points in Sui and Tang Dynasties is $637.0 \mathrm{~m}$. It can be inferred that the inhabitants from the Han Dynasty to the Northern and Southern Dynasties were afraid of the threat of flooding, so their living places were chosen in high terrain. The flood control technology of the Tang Dynasty was more advanced than before, so the living place was not afraid of the threat of flooding even in the lower terrain. In this paper, we infer that the period from Han to the North and South Dynasties may have been more seriously affected by floods than the Sui and Tang dynasties, and therefore chose a higher terrain to escape from floods. It is also possible that Han Dynasty residents chose to live on the mountain to escape from war, so the elevation of the ancient site is relatively high. From Han to Tang, the site with the lowest elevation is the site of Shujilou in the southeast of Shangluo City: $222 \mathrm{~m}$ and the highest site is the site of Maliantan in the northwest of Baoji City: 1957m. The elevation distribution range of site sites in Shaanxi Province is $222 \sim 1957 \mathrm{~m}$, with an average elevation of $866.2 \mathrm{~m}$, and the frequency is concentrated at about $1000 \mathrm{~m}$. The distribution of site sites is closely related to altitude, and after greater than a certain altitude, site sites decrease with increasing altitude. This indicates that there are fewer ancient human activities at high altitudes, which is consistent with the relatively strong dependence of ancient humans on the natural environment.

\subsubsection{Slope}

The slope represents the direction of the terrain, the smaller the slope the flatter the terrain, the larger the slope the steeper the terrain [24]. The slope directly affects people's choice of place to live, and the plain area is more suitable for people to live than the mountainous area. Besides, the slope affects the degree of scouring of the surface by the river. The slope of the large flow rate, the surface scouring serious erosion leads to soil erosion, is not conducive to the growth of crops. On the contrary, the slope is small and the flow rate is low, the nutrients in the soil are easily deposited for the growth of crops, Therefore, slope influences people's choice of where to live.

The slope data of the site points were extracted by ArcMap on DEM in Shaanxi Province (see Table 1). The slope is classified into five grades by the slope grading index in Table 1: flat slope $\left(0 \sim 3^{\circ}\right)$, gentle slope $\left(3 \sim 10^{\circ}\right)$, medium slope $\left(10 \sim 25^{\circ}\right)$, steep slope $\left(25 \sim 50^{\circ}\right)$, and sharp slope $\left(>50^{\circ}\right)$. The slope distribution of site sites on different slopes during the two periods was mapped according to the slope change (see Figure 5). From Figure 5 and Table 1, it can be seen that there are 682 and 238 sites distributed between slope $0 \sim 3^{\circ}$ in Shaanxi Province 
from Han Dynasty to North and South Dynasties and Sui and Tang Dynasties, accounting for $42.7 \%$ and $63.6 \%$ of the total number of sites in each period, respectively; 427 and 87 sites distributed between slope $3 \sim 10^{\circ}$, accounting for $26.7 \%$ and $23.3 \%$ of the total number of sites in each period, respectively; and 448 and 44 sites distributed between slope 10 25 , accounting for $28.1 \%$ and $11.8 \%$ of the total number of sites in each period, respectively; There are 448 and 44 points distributed between 10 and $25^{\circ}$ slope, accounting for $28.1 \%$ and $11.8 \%$ of the total number of sites in each period, respectively; 40 and 5 points distributed between 25 and $50^{\circ}$ slope, accounting for $2.5 \%$ and $1.3 \%$ of the total number of sites in each period, respectively. The average slope of the site sites from Han to North and South Dynasties is $7.1^{\circ}$, and the average elevation of the site sites in Sui and Tang Dynasties is $4.3^{\circ}$. The Han to the North and South Dynasties and the Sui and Tang dynasties both have the most sites distributed on flat slopes, accounting for $42.7 \%$ and $63.6 \%$ of the total, respectively. The number of site locations tends to decrease as the slope increases. The proportion of sites distributed on the middle and steep slopes in the Sui and Tang dynasties is significantly reduced compared to the Han and Northern and Southern Dynasties periods. Through comparison, it is found that the distribution of site sites in the Sui and Tang dynasties tends to be more in areas with less undulating terrain. Generally speaking, people choose to live on flat slopes and gentle slopes, and the analysis results are more consistent with the actual situation.

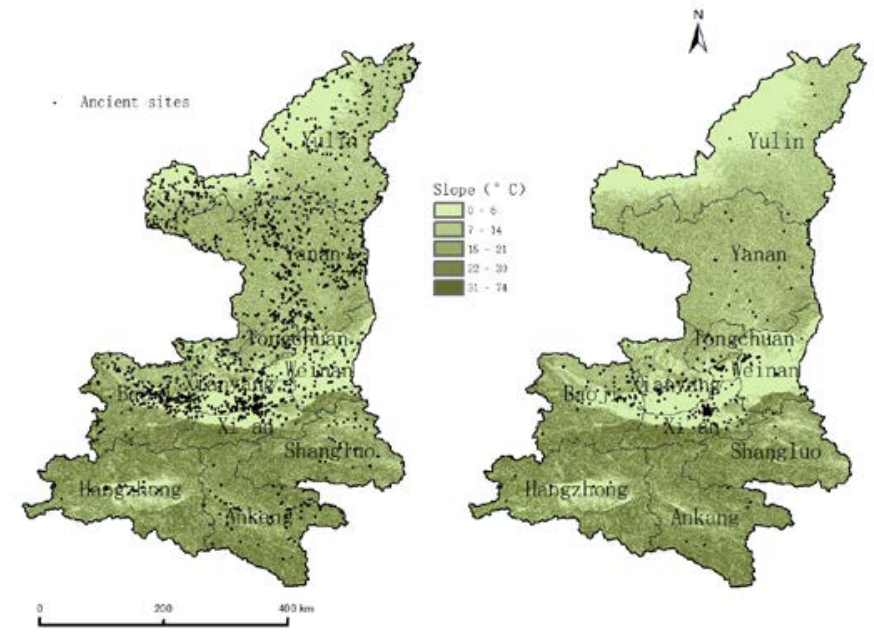

Fig.5 Slope of ancient sites in the Han dynasties-Northern and Southern dynasties(left) and in the Sui dynasties-Tang dynasties (right)

Tab 1 Statistical table of ancient sites slope

\begin{tabular}{ccccc}
\hline \multicolumn{1}{c}{ slope/ $^{\circ}$} & $0 \sim 3$ & $3 \sim 10$ & $10 \sim 25$ & $25 \sim 50$ \\
\hline $\begin{array}{c}\text { percentage from Han to } \\
\text { North and South } \\
\text { dynasties } / \%\end{array}$ & $42.7 \%$ & $26.7 \%$ & $28.1 \%$ & $2.5 \%$ \\
percentage of Sui and & & & $11.8 \%$ & $1.3 \%$ \\
Tang dynasties /\% & $63.6 \%$ & $23.3 \%$ & & \\
\hline
\end{tabular}

3.2.3. Aspect 
Aspect is one of the geomorphological forms, which has a great influence on the mountain climate and precipitation. The southern slope facing the sun in the northern hemisphere receives more radiation than the northern slope, so people in the northern hemisphere prefer to choose the southern slope or the southwestern or southeastern slope to build rents to get maximum light. Experts usually classify slope orientation into four categories according to the degree of suitability for living: most suitable $>$ suitable > relatively suitable > unsuitable: 1 . the most suitable aspect of living in the south; 2 . inhabitable slopes, southeast, and southwest; 3. more habitable slopes, northwest, and north; 4 . inhabitable slopes, including east, west, and northeast.

In this paper, GIS technology was used to analyze the study area to reveal the aspect distribution characteristics of the site, extracting the aspect data of the site points distributed in Shaanxi Province. A statistical map of aspect (see Figure 6) and a statistical table of suitability (see Table 2) were drawn for the study area. From Figure 6 and Table 2, it can be seen that there are 265 and 64 sites distributed in the most suitable aspect in Shaanxi Province during the Han to North and South Dynasties and Sui and Tang dynasties, accounting for $16.7 \%$ and $17.5 \%$ of the total number of sites in each period, respectively; There are 468 and 105 sites distributed on the suitable aspect, accounting for $29.5 \%$ and $28.8 \%$ of the total number of sites in each period, respectively; 294 and 83 sites distributed on the more suitable aspect, accounting for $18.5 \%$ and $22.7 \%$ of the total number of sites in each period, respectively; 561 and 113 sites distributed on the unsuitable aspect, accounting for 35.3\% and $31.0 \%$ of the total number of sites in each period, respectively. The aspect (most suitable, suitable, more suitable) distribution of the sites suitable for human habitation was the largest from Han to North and South Dynasties and Sui and Tang periods, accounting for $64.7 \%$ and $69.0 \%$ of the total respectively. Summary analysis of the Han to Tang period: the most inhabitable site sites in Shaanxi Province are the most numerous, accounting for $16.8 \%$ of the total number of sites. The percentages of the most suitable, suitable, relatively suitable, and unsuitable aspect sites are $16.8 \%, 29.3 \%, 19.3 \%$, and $34.5 \%$ respectively. The results of the analysis show that $65.5 \%$ of the ancient site points from the Han to the Tang dynasties were oriented towards the habitable aspect. Influenced by subjective variability, a small number of the aspect facing uninhabitable. It is consistent with the previous analysis that the ancient people had a tendency to choose the aspect, and they would choose the aspect that received relatively more solar radiation. Academics generally believe that the ancient people will take full account of the impact of aspects on production and life when choosing a place to live. From the above analysis, it can be seen that the vast majority of the sites are located on a more suitable aspect, this leads to the conclusion that the topography of Shaanxi Province changed relatively little from the Han to Tang periods. 


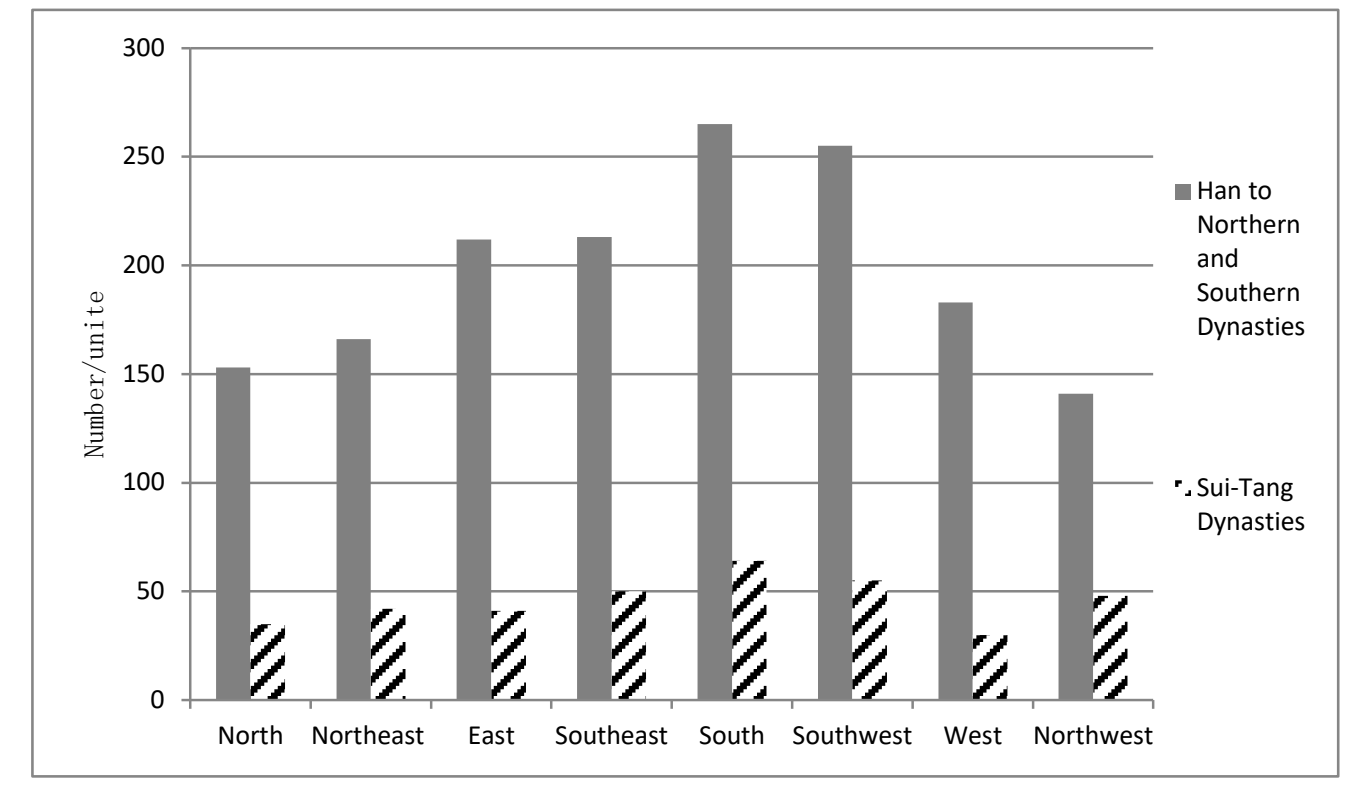

Fig.6 Statistical chart of the study area aspect

Tab 2 Statistical table of suitability

\begin{tabular}{|c|c|c|c|c|}
\hline suitability for living & $\begin{array}{r}\text { Most } \\
\text { suitable }\end{array}$ & suitable & $\begin{array}{l}\text { relatively } \\
\text { suitable }\end{array}$ & unsuitable \\
\hline $\begin{array}{c}\text { percentage from Han to } \\
\text { North and South dynasties } \\
\qquad 1 \%\end{array}$ & 16. $7 \%$ & $29.5 \%$ & $18.5 \%$ & $35.3 \%$ \\
\hline $\begin{array}{l}\text { percentage of Sui and } \\
\text { Tang dynasties } 1 \%\end{array}$ & $17.5 \%$ & $28.8 \%$ & $22.7 \%$ & $31.0 \%$ \\
\hline
\end{tabular}

\subsubsection{Rivers}

In ancient times, it was troublesome to fetch water by manpower, so people lived closer to the river. Human civilization also spread along rivers, and rivers are very important to people. But rivers are prone to flooding, and people do not choose to live in areas too close to them. Generally, they would choose to live near but not close to the river [25], usually within $10 \mathrm{~km}$. GIS software was used to analyze the multi-loop buffer zone of rivers in Shaanxi Province, and then to draw a statistical map of the distance of site sites from rivers (see Figure 7) and a statistical table of the distance of site sites from rivers (see Table 3), to analyze the distance relationship between the sites and rivers in the Han and Tang dynasties. 


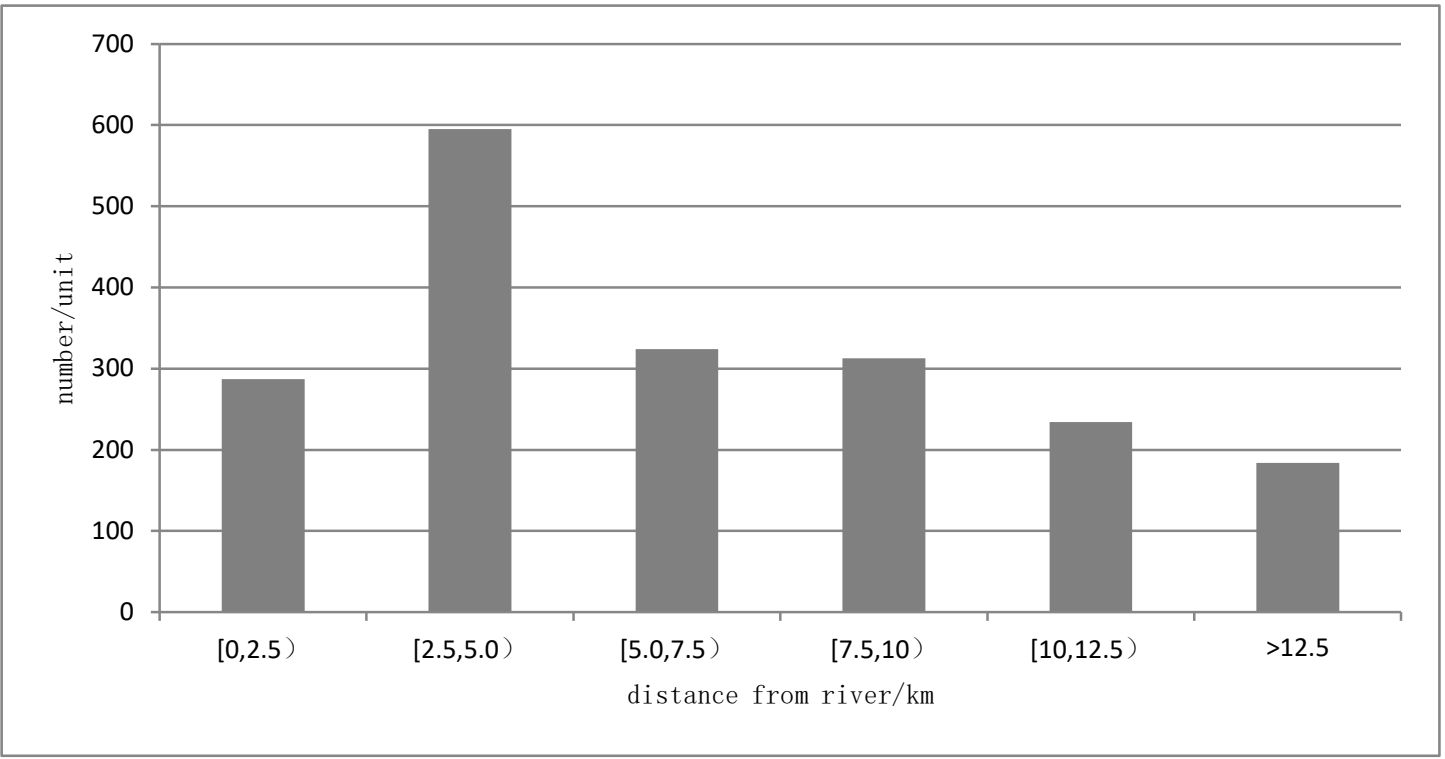

Fig.7 Statistical chart of ancient sites distance away from the river

Tab 3 Statistical chart of ancient sites distance away from the river in the Han dynasties-Tang dynasties

\begin{tabular}{cccccc}
\hline distance $/ \mathrm{km}$ & $0 \sim 5$ & $5 \sim 7.5$ & $7.5 \sim 10$ & $10 \sim 12.5$ & $>12.5$ \\
\hline percentage $1 \%$ & 45.6 & 16.8 & 16.2 & 12.1 & 9.5 \\
\hline
\end{tabular}

From Figure 7 and Table 3, it can be seen that 882 sites were distributed within $5 \mathrm{~km}$ from the river during the Han to Tang periods, accounting for $45.6 \%$ of the total; There are 324 sites within $5 \sim 7.5 \mathrm{~km}$ from the river, accounting for $16.8 \%$ of the total; 313 sites within $7.5 \sim 10 \mathrm{~km}$ from the river, accounting for $16.2 \%$ of the total; 234 sites within $10 \sim 12.5 \mathrm{~km}$ from the river, accounting for $12.1 \%$ of the total; 184 sites greater than $12.5 \mathrm{~km}$, accounting for $9.5 \%$ of the total. Conclusion: there is a close relationship between the distribution of site locations and river distances from the Han to Tang periods, the sites are concentrated within $10 \mathrm{~km}$ from the river, and the further away from the river, the less the sites are distributed. The number of sites decreases gradually with increasing distance from the river and is characterized by a linear distribution. In contrast to the sites from the Han to the Northern and Southern Dynasties, the Sui and Tang sites are distributed at a more distant location of the river. It can be inferred that the inhabitants of the Sui and Tang dynasties were less dependent on rivers, and flood control technology was also more advanced than before the Han Dynasty. Therefore, the site is chosen at a relatively low elevation and there is no concern about the threat of flooding. On the other hand, during the Tang Dynasty, the "vertical well" water collection tool was invented, reducing people's dependence on rivers.

\section{Results and Discussion}

The geographical distribution of ancient sites is the result of a combination of natural and human factors. Using modern technical means to study the factors influencing the temporalspatial distribution of ancient sites will be useful for experts and scholars in various fields to understand ancient sites. This paper uses GIS spatial analysis to explore the relationship between the aggregation characteristics of ancient sites and their geographical location and 
geographic environment, and concludes as follows:

1) The ancient sites are influenced by geography and human environment, and are affected by topography, slope, aspect, and regime, and are concentrated in the Guanzhong Plain and scattered in other areas.

2) The ancient sites are clustered within $10 \mathrm{~km}$ from the river, The farther the distance from the river, the fewer the sites are distributed, As the distance from the river increases, the number of sites gradually decreases, showing a linear distribution.

3) Economic development is also a factor affecting the distribution of ancient sites, and the economy affects the number of population. During the Han and Tang dynasties, the Guanzhong Plain was more economically developed and densely populated than the northern Shanxi plateau and the southern Shanxi Mountains. Therefore, the number of ancient sites in the Guanzhong Plain during the Han and Tang dynasties is characterized by aggregated distribution.

The temporal-spatial distribution of ancient site locations in Shaanxi Province is the result of a combination of natural factors such as topography, geomorphology, hydrology, and roads, as well as human factors such as regime changes, wars, and the degree of support from those in authority. The natural environment of the study area, such as topography, geomorphology, and the distance between the site and the river, are all factors that must be considered in studying the spatial distribution pattern of ancient sites. GIS technology can present the temporal-spatial distribution of site locations in relation to the geographic environment in the form of graphs and charts, enabling further scientific improvement. Although GIS is accurate in spatial analysis of geographic geography, there is no way to obtain the ancient natural environment, and the analysis is only of the modern geographic environment, coupled with other factors that make it impossible for the results of the analysis to correspond exactly to the actual situation at the time. Therefore, the study of the temporalspatial distribution pattern of ancient sites needs more mature theoretical and technical support.

\section{Conclusions}

The topography, climate, precipitation, regime change, economic development, population size, and Fenghui culture of Shaanxi Province combine to form the distribution characteristics of ancient sites. A variety of landforms exist in Shaanxi Province: plateaus, plains, mountains, hills, basins, etc. Among them, the plains have open terrain, abundant precipitation, developed agriculture, and are most suitable for people to live; the mountains and plateaus are not well developed in terms of transportation, and the plateau is sparsely populated with livestock, which is the least suitable for people to live in. Influenced by topography and climate precipitation, the ancient sites are concentrated in the plains, while the mountains and plateaus show a discrete distribution. The Han Dynasty was the most 
powerful empire in China's history, with a developed economy and a large population, and there were many ancient sites during the Han Dynasty. During the Wei, Jin, and North and South Dynasties, the climate was dry and cold, the natural environment began to deteriorate, and the society was in turmoil. According to incomplete statistics, 611 wars took place during this period, which lasted for a long time, involved a wide range, and caused a lot of damage[21], this has led to a sharp decline in population, with only 374 site locations in 361 years of history. China's climate was generally warm during the Sui and Tang dynasties and only began to cool towards the end of the Tang Dynasty [20]. However, there were fewer wars during the Sui and Tang dynasties and they lasted for a short period, so there are not many ancient sites from the Sui and Tang dynasties.

\section{Declaration:}

1. Availability of data and materials

1) The data of ancient sites in this paper are sourced from the "Third National Cultural Relics Census Series in Shaanxi Province

2) Vector data source National Basic Geographic Information Center official website: http://www.ngcc.cn/ngcc/

3) Raster data source of geospatial data cloud platform: http://www.gscloud.cn/

4) ArcGis software source: https://www. geoscene. cn/

2. Competing interests

The authors declare no competing financial interests.

3. Funding

'Not applicable'

4. Authors' contributions

'Not applicable'

5. Acknowledgements

'Not applicable' 


\section{Reference:}

6. R ICHA R DSG. Tourism attraction systems: Exploring cultural behavior. J. Annals of Tourism R esearch, 2002, 29(4): 1048-1064.

7. LIM, WUB, CAI L. Tourism development of World Heritage Sites in China: Ageographic perspective. J. Tourism Management, 2008, 29(2): 308-319.

8. CominelliF, GreffeX. Intangible cultural heritage: Safeguard-ing orcreativity. J. City, Culture and Society, 2012, (3): 245-250.

9. Huang R., Zhu C., Deng C., The influence of Holocene environmental evolution on the distribution of Neolithic sites in Huaihe River Basin, Anhui. J. Geography, 2005, 60 (5): 742-750.

10. Zhu A., Zhou Y., Chen J., etc. Research on the spatial and temporal evolution of cultural relics in Hubei Province - - Taking cultural relics protection units as an example. J. Economic geography, 2016, 36 (11): 184-191.

11. Huang R., Zhu C., Deng C.. The influence of Holocene environmental evolution on the distribution of Neolithic sites in Huaihe River Basin, Anhui. J. Geography, 2005, 60 (5): 742-750.

12. Deng H., Chen Y., Jia J., etc. Evolution of the distribution of ancient cultural sites in the plains of the middle reaches of the Yangtze River since 8500 a BP. J. Geography, 2009, 64 (9): 1113-1125.

13. Dai X., Que W.. Temporal and spatial distribution characteristics and causes of Chinese mining heritage-Based on the perspective of cultural heritage protection units. J. Geography research, 2011, 30 (4): 747-757.

14. Wu J., Pan H., Du Y.. The spatial and temporal evolution characteristics and influencing factors of Chinese historical garden heritage. J. Human geography, 2016,147 (1): 50-56.

15. Zhang C.. Tourism and Heritage Protection: Case-based Theoretical Study. M. Tianjin: Nankai University Press, 2008: 22-26.

16. Tian W.. Concise history of Xinjiang. M. Urumqi: Xinjiang People's Publishing House, 2009: 16-45.

17. Wang M., Wang B.. Wusun Research. M. Urumqi: Xinjiang People's Publishing House, 1983: 19-30.

18. Zhou J., Chen C.. Research on Ethnic Anthropology of Ancient Residents of the Silk Road. M. Urumqi: Xinjiang People's Publishing House, 1994: 1-33.

19. Jiang X., Li Z., Chen X., etc. Late Holocene pollen records and climate change of aeolian sand deposits in Yili River Valley, Xinjiang. J. Desert of China, 2011, 31 (7): 855-861.

20. Xiong H., Zhong W., Taxi Platti, etc. Coupling relationship between natural and human historical 
changes in the southern margin of the Tarim Basin. J. Geography, 2000, 55 (2): 211-219.

21. Wang F., Zhang X., Yang Z., etc. Temporal and spatial distribution and variability of Yili Valley cultural sites since 4000 aBP. J. Desert of China, 2015, 35 (4): 1123-1129.

22. Hu K., Mo D., Mao L., etc. Spatial analysis of human settlement site selection in Wuding River Basin during the middle Holocene and its geomorphological and environmental significance. J. Geography, 2011, 31 (4): 415-420.

23. Editor-in-chief, Shaanxi Provincial Bureau of Cultural Relics, Shaanxi Provincial Third National Cultural Relics Survey Series. M. Xi ' an, Shaanxi Tourism Press, 2012, 06.

24. Journal of Archaeology, 1991, (4). 1991, (2). 1992, (3). 1995, (2). 1997, (3). 2012 (3). Cathaysian Archaeology, 1987, (1). 1991, (4). 1995, (2). 2001, (1).

25. Xie L., Li Y., Wang H., etc. Research on the relationship between ancient kiln sites and geographical environment supported by GIS - - Taking Fujian Province as an example. J. Cultural relics protection and archaeological science, 2013, 25 (04): 100-105.

26. Zhu K.. Preliminary study on climate change in China in the past five thousand years. C. Zhu Kezhen's collection.Scientific Press, 1979, 475-498.

27. Ge Q.. Climate change in China. M. Beijing: Science Press, 2011: 277 - 283.

28. Zhu C., Wu L., Li L., etc. Research progress of Holocene environmental archaeology in the Yangtze River Basin. J. Geography, 2014, (09): 1268-1283.

29. Guo L., He Q., Dano ROELVINK, et al. Research and progress on the simulation of dynamic geomorphological systems at medium and long time scales along the estuary coast. J. Geography, 2013, (09): 1182-1196.

30. He T., Wang N., Huang Y., Cheng H.. Changes of surface water environment in Maowusu ancient city inversion. J. China desert, 2010, (03): 471-476. 


\section{Figures}

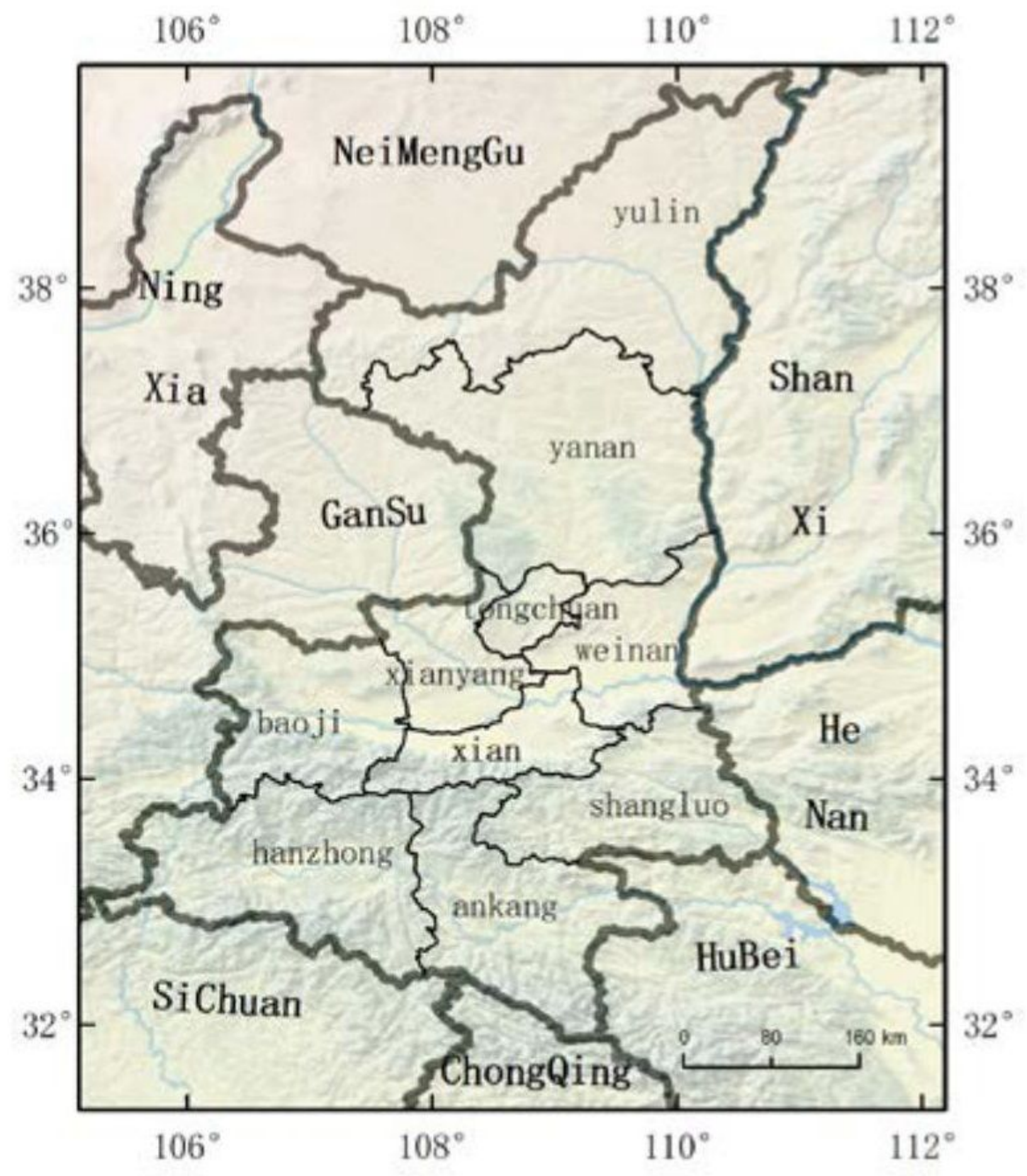

Figure 1

Location-based map of Shaanxi Note: The designations employed and the presentation of the material on this map do not imply the expression of any opinion whatsoever on the part of Research Square concerning the legal status of any country, territory, city or area or of its authorities, or concerning the delimitation of its frontiers or boundaries. This map has been provided by the authors. 


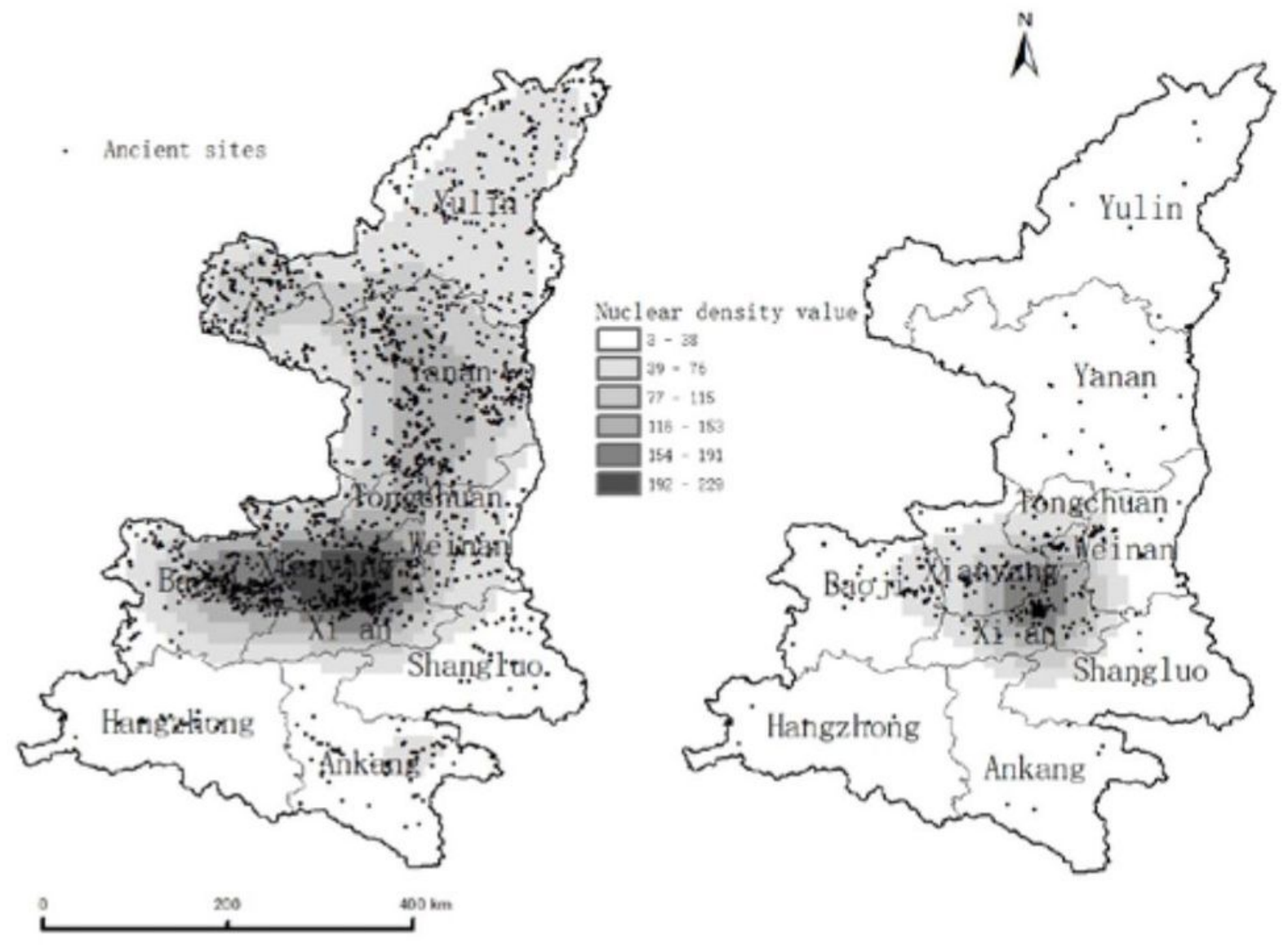

Figure 2

Density of ancient sites in the Han dynasties-Northern and Southern dynasties(left) and in the Sui dynasties-Tang dynasties (right) Note: The designations employed and the presentation of the material on this map do not imply the expression of any opinion whatsoever on the part of Research Square concerning the legal status of any country, territory, city or area or of its authorities, or concerning the delimitation of its frontiers or boundaries. This map has been provided by the authors. 

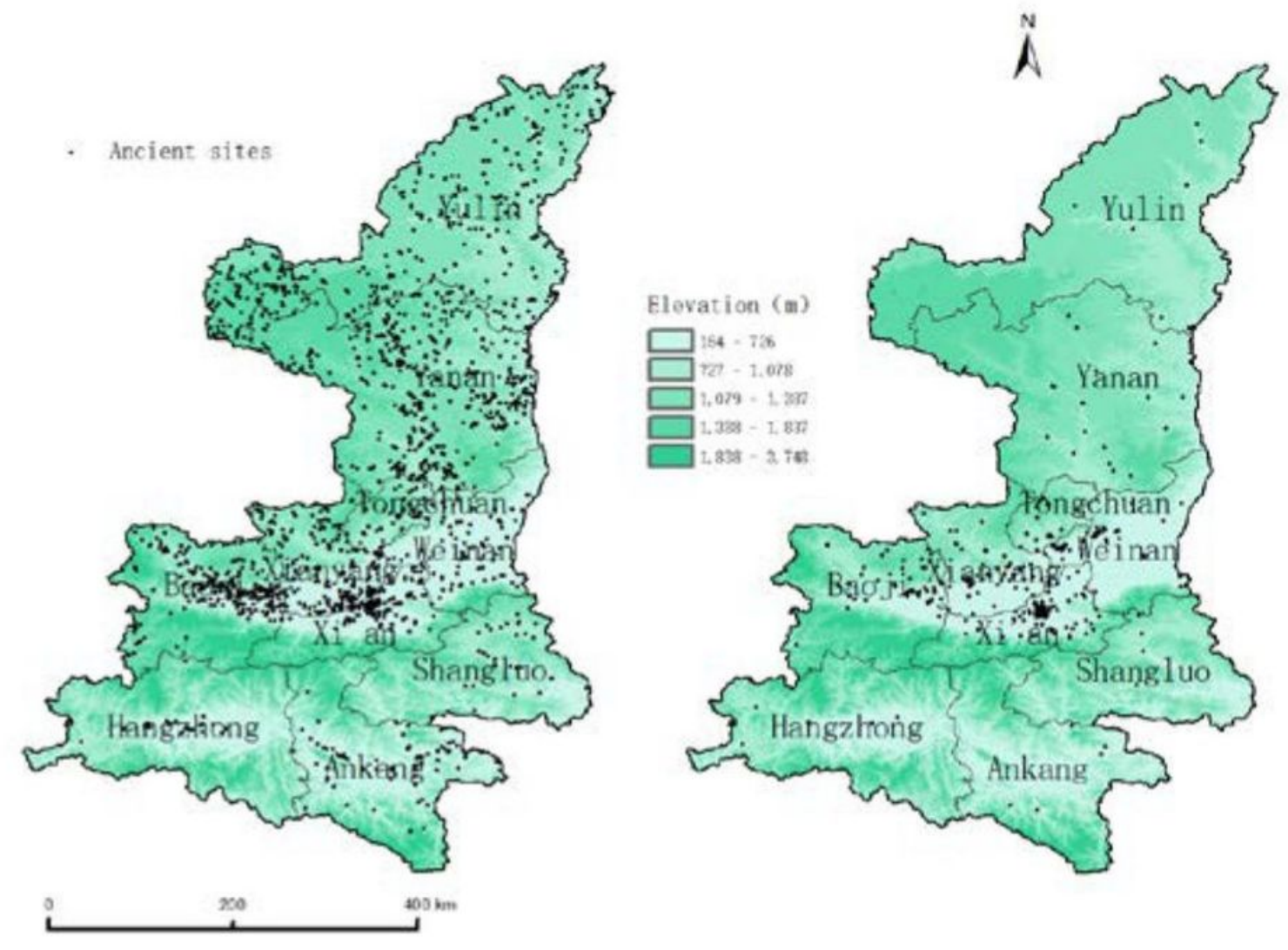

Figure 3

Altitude of ancient sites in the Han dynasties-Northern and Southern dynasties(left) and in the Sui dynasties-Tang dynasties (right) Note: The designations employed and the presentation of the material on this map do not imply the expression of any opinion whatsoever on the part of Research Square concerning the legal status of any country, territory, city or area or of its authorities, or concerning the delimitation of its frontiers or boundaries. This map has been provided by the authors. 


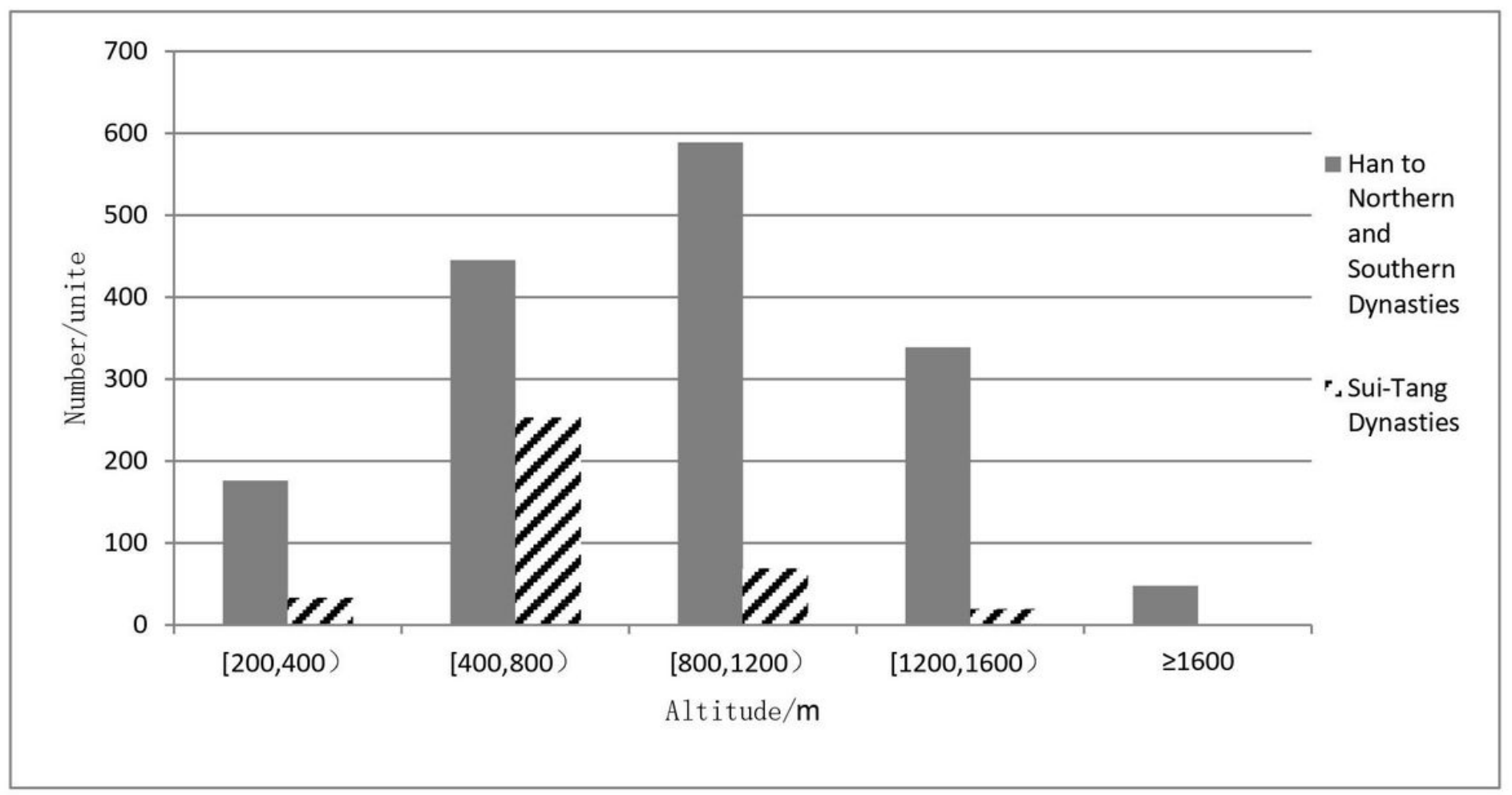

Figure 4

Altitude frequency chart of ancient sites 


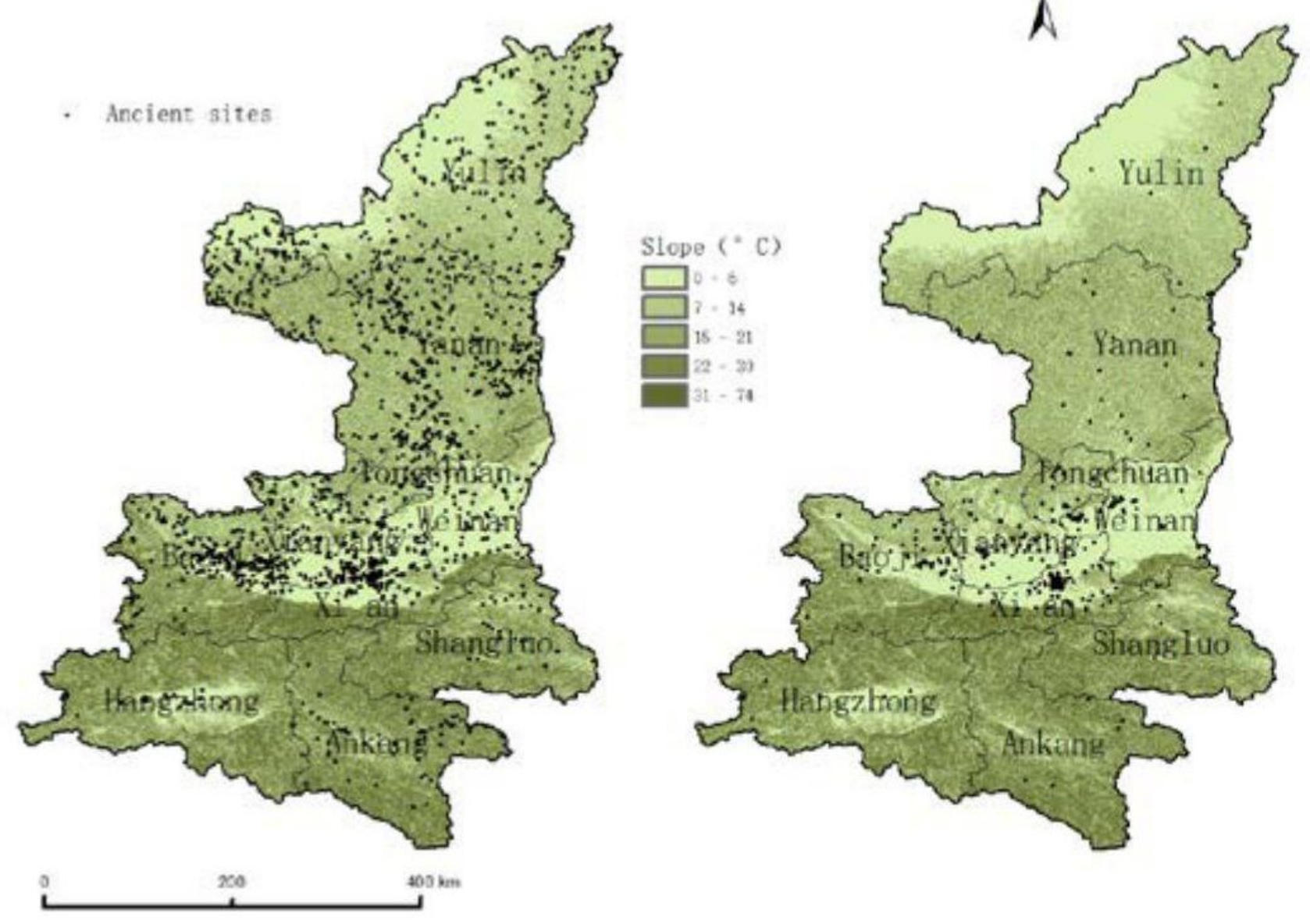

Figure 5

Slope of ancient sites in the Han dynasties-Northern and Southern dynasties(left) and in the Sui dynasties-Tang dynasties (right) Note: The designations employed and the presentation of the material on this map do not imply the expression of any opinion whatsoever on the part of Research Square concerning the legal status of any country, territory, city or area or of its authorities, or concerning the delimitation of its frontiers or boundaries. This map has been provided by the authors. 


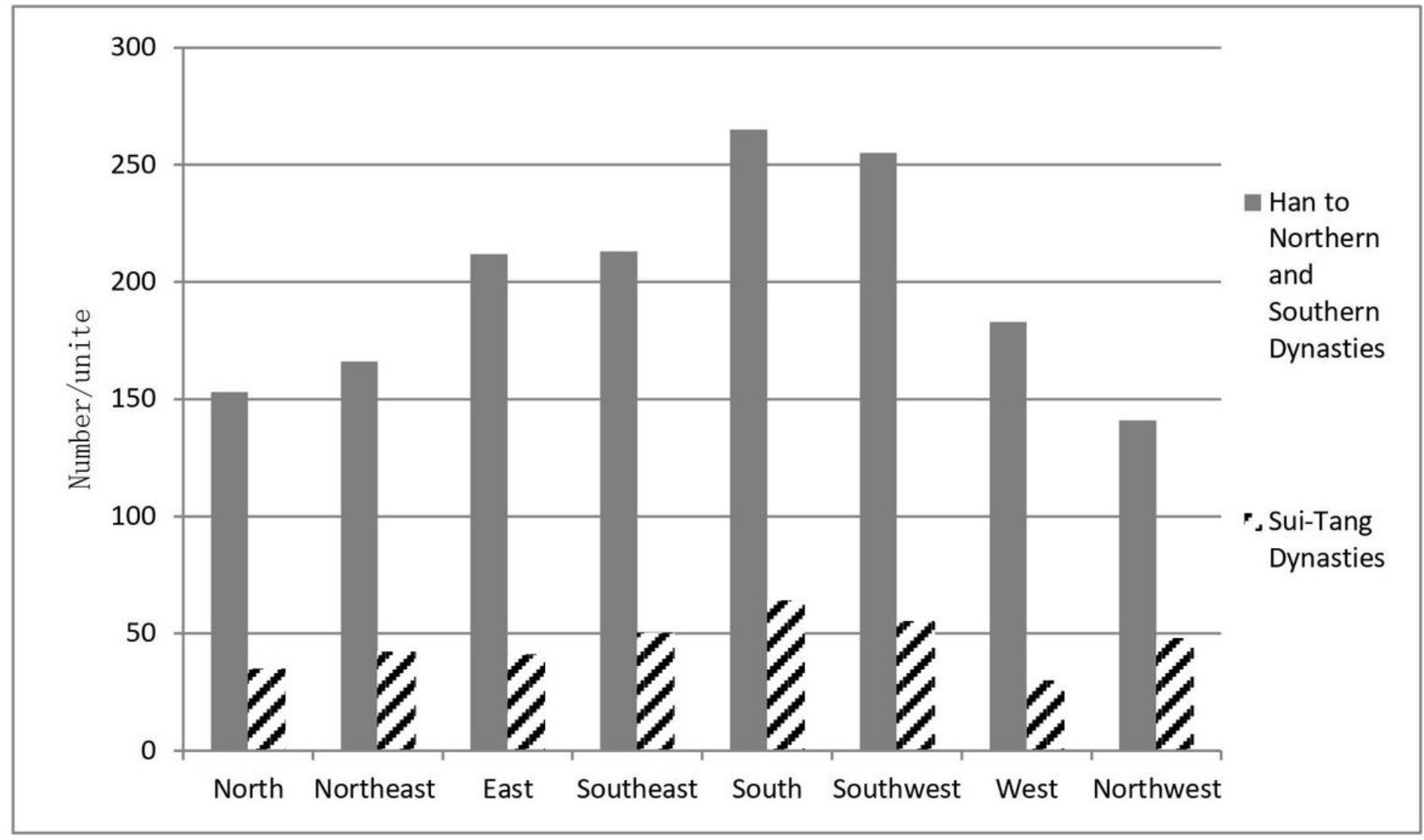

Figure 6

Statistical chart of the study area aspect

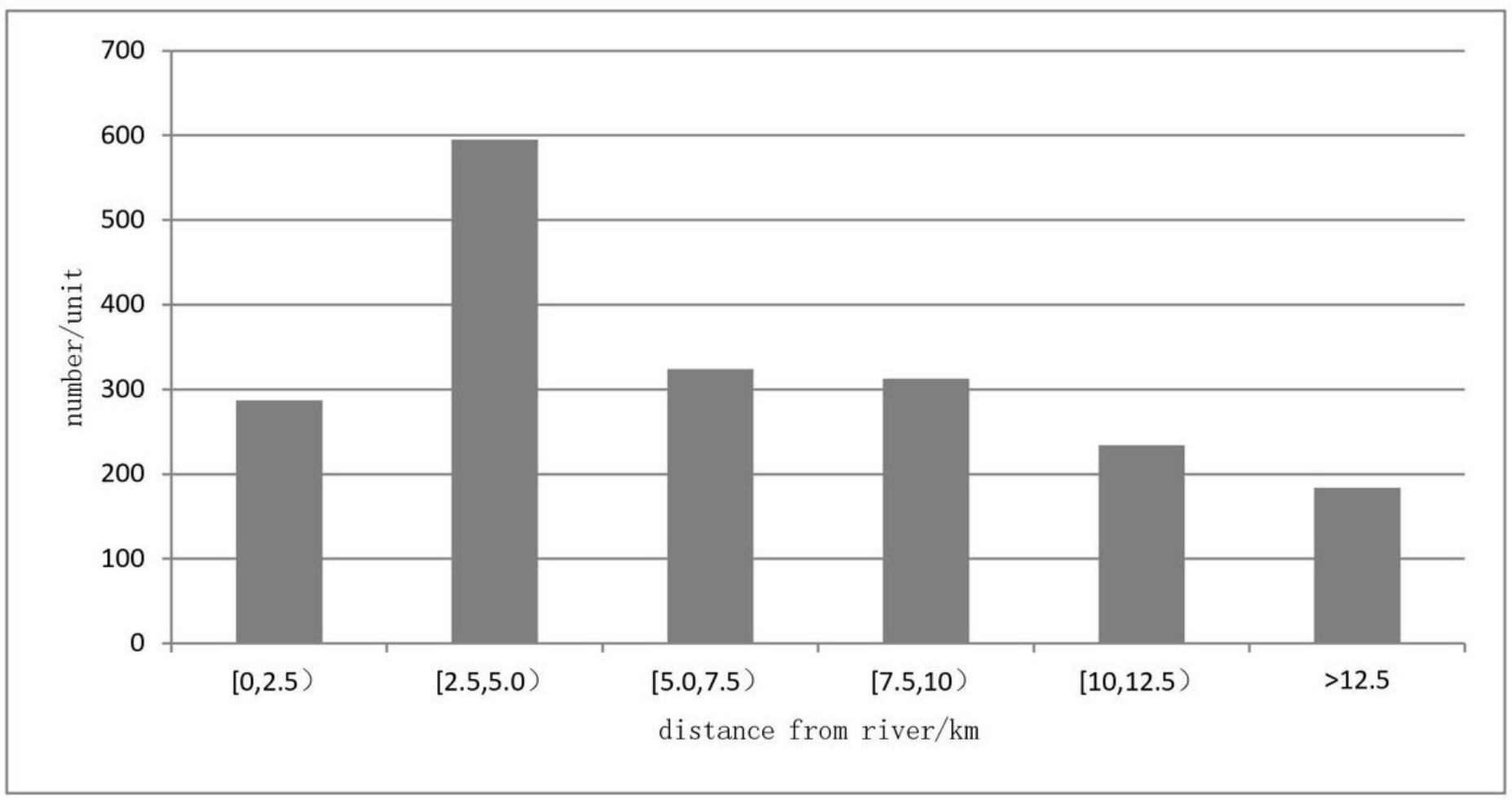


Figure 7

Statistical chart of ancient sites distance away from the river 